\title{
RACIONALIDADE E MÉTODO: DUAS CONTRIBUIÇÕES DE FERNANDO CARDIM DE CARVALHO À TEORIA PÓS-KEYNESIANA
}

\begin{abstract}
Fábio Henrique Bittes Terra ${ }^{a}$
aProfessor da Universidade Federal do ABC Paulista (UFABC) e do Programa de Pós-Graduação em Economia da Universidade Federal de Uberlândia (PPGE-UFU), e pesquisador do CNPq. São Paulo, SP, Brasil. ORCID: http://orcid.org/0000-0002-2747-7744.

Recebido em 06 dezembro 2018

Aceito em 14 março 2019

RESUMO: Em meio à vasta produção do Professor Cardim de Carvalho, encontram-se duas contribuições que ele ofereceu à teoria pós-keynesiana, quais sejam, as discussões sobre a racionalidade sob incerteza e método. Mais do que apenas dois conceitos estanques, Professor Cardim de Carvalho os relaciona ao debater o método de Keynes na Teoria Geral do Emprego, do Juro e da Moeda, argumentando que a compreensão da racionalidade humana coloca em contato o agente observador e o agente observado, fazendo com que o sujeito teórico apreenda o sujeito teorizado - o consumidor, o empresário, o especulador - não como um pressuposto, mas um dado da realidade. $\mathrm{O}$ que aproxima o analista do analisado é aquele compreender a racionalidade deste e isto é essencial para que Keynes, o sujeito, teorize sua economia monetária da produção, o objeto. Apresentar estas contribuições é o objetivo deste artigo.
\end{abstract}

PALAVRAS-CHAVE: Fernando Cardim de Carvalho; Keynes; racionalidade; método.

CLASSIFICAÇÃO JEL: E12; B41; D01; D91. 


\title{
RATIONALITY AND METHOD: TWO CONTRIBUTIONS OF FERNANDO CARDIM DE CARVALHO TO THE POST KEYNESIAN THEORY
}

\begin{abstract}
Amongst his prolific bibliographical production, Professor Cardim de Carvalho has given two contributions to the Post Keynesian theory in the topics of rationality under uncertainty and method. Further than two isolated concepts, Professor Cardim de Carvalho intertwines them to discuss Keynes' method in The General Theory of Employment, Interest, and Money. Professor Cardim de Carvalho argues that the comprehension of the human rationality puts both the observer and observed agents in touch and allows the theorist to model the theoretical agent consumers, entrepreneurs, financial investors - not as an assumption, but as evidence of reality. Apprehending human rationality is what approximates the analyst to the analyzed individual and this way key to Keynes, the subject, approach his object, the monetary economy of production. Thus, this paper aims to present these contributions by Professor Cardim de Carvalho's.
\end{abstract}

KEYWORDS: Fernando Cardim de Carvalho; Keynes; rationality; method. 


\section{INTRODUÇÃO*}

A obra do professor Cardim de Carvalho estendeu-se por diversos temas, sobretudo em questões monetárias, bancárias e relacionadas à teoria econômica. Nessa última área, seus esforços se dedicaram a discutir o papel da racionalidade humana sob incerteza e as características essenciais do método de Keynes na Teoria Geral do Emprego, do Juro e da Moeda (TG) (KEYNES, 1964). ${ }^{1}$ Mais do que contribuições estanques, que se afiliariam apenas aos seus respectivos temas na teoria pós-keynesiana, Professor Cardim de Carvalho relaciona ambos os elementos, argumentando que a compreensão da racionalidade humana sob incerteza é um aspecto fundamental do método de Keynes na TG.

Em uma franca crítica ao agente representativo do mainstream econômico, hipoteticamente definido como detendo racionalidade ilimitada, o professor Cardim de Carvalho considera que a compreensão da racionalidade humana sob incerteza foi elemento central para que Keynes teorizasse a economia monetária da produção. Como o método é o meio de contato entre sujeito e objeto em qualquer investigação científica, não postular uma racionalidade, mas a perceber como ela de fato é - inclusive reconhecer-se raciocinando tal qual o sujeito analisado -, foi parte do método de Keynes na TG.

O objetivo deste artigo é mostrar estas duas contribuições do professor Cardim de Carvalho à teoria pós-keynesiana - diga-se de passagem, em geral, elas são as menos referenciadas dentre os vários avanços feitos por ele ao pós-Keynesianismo, embora sejam debates de fronteira e, inclusive, na questão do método na TG, seu argumento é uma discussão feita apenas por ele, como se pode notar em Ferrari Filho e Terra (2016). Este artigo não descreve as contribuições do professor Cardim de Carvalho repassando cronologicamente cada um dos seus textos sobre os temas aqui analisados, não se fazendo, portanto, uma revisão bibliográfica como método de exposição. Neste particular, a estratégia de exposição do artigo centra-se em sintetizar a lógica e a argumentação das contribuições do professor Cardim de Carvalho acerca da racionalidade sob incerteza e do método como um todo, isto é, como uma espécie de modelo que se pode extrair dos textos dele.

* O apoio financeiro do CNPq a esta pesquisa é reconhecido com gratidão

1 Os artigos sobre racionalidade são Keynes on probability, uncertainty and decision making (CARVALHO, 1988), Decision-making under uncertainty as drama: Keynesian and Shacklean themes in three of Shakespeare's tragedies (CARVALHO, 2002), e Keynes on expectations, uncertainty and defensive behavior, de 2015, enquanto que o artigo sobre o método em Keynes é As características essenciais do método de Keynes na Teoria Geral (CARVALHO, 2003). Em seu clássico livro, Mr. Keynes and the Post-Keynesians (CARVALHO, 1992), há também uma discussão sobre método, porém com um recorte de sociologia científica, em que o professor Cardim de Carvalho busca, por um lado, apresentar os postulados que formam o núcleo duro do paradigma pós-Keynesiano e, por outro lado, situá-lo dentre os vários paradigmas da ciência econômica, como esforço para clarificar as diferenças entre o pós-Keynesianismo e o Keynesianismo da síntese neoclássica. 
Antes de apresentar a estrutura do artigo, peço licença para cometer duas ousadias acadêmicas. A primeira delas é usar a primeira pessoa do singular como pessoa verbal neste parágrafo para informar a outra audácia. Eu, neste artigo, pela própria natureza dele - uma homenagem ao professor Cardim de Carvalho via apresentação de dois importantes avanços que ele ofereceu ao pós-Keynesianismo -, usarei adjetivos ao longo do texto, algo pouco afeito à rigorosidade da escrita científica. Farei isso para ressaltar o brilhantismo que se pode perceber em suas ideias e como convite para que o leitor interessado vá deste artigo para os que realmente importam, os do professor Cardim de Carvalho. Pois bem, feita a ressalva, a segunda seção do artigo apresenta a racionalidade humana sob incerteza na visão do professor Cardim de Carvalho e a terceira seção destaca sua contribuição acerca do método de Keynes na TG. Por fim, tecem-se as considerações finais.

\section{A RACIONALIDADE HUMANA SOB INCERTEZA}

Carvalho $(1988,2002,2015)$ preocupou-se com a racionalidade sob incerteza, isto é, como os indivíduos tomam decisões desconhecendo previamente, e com a impossibilidade de conhecerem, os resultados de suas decisões. Todos os artigos resgatam a forma pela qual Keynes em seu Treatise on Probability (1921) concebeu a racionalidade sob incerteza de modo que, em meio a uma das controvérsias centrais das discussões da teoria pós-keynesiana, qual seja, se houve ruptura ou continuidade entre as obras de Keynes $^{2}$ no tempo, Carvalho $(1988,2015)$ se posiciona a favor da continuidade. Além de Keynes, outra referência sempre presente é Shackle (1979), que ofereceu três elementos presentes na forma pela qual o professor Cardim de Carvalho entendeu a racionalidade sob incerteza: os figments of imagination, a criação do futuro pelas decisões humanas e a crucialidade das decisões. Estes três itens de Shackle foram cuidadosamente costurados por Carvalho (1988, 2002, 2015) com Keynes (1921 e 1964), permitindo-lhe modelar a racionalidade envolvida na tomada de decisão sob incerteza. ${ }^{3}$

Carvalho (1988) é o que resgata como Keynes (1921) apreendeu a racionalidade humana e que reaparecerá, para outras finalidades, nos textos daquele autor de 2003 e 2015. Os indivíduos acumulam conhecimento direto, formado por um conjunto de

2 Para mais sobre as controvérsias, inclusive a mencionada, veja: Ferrari Filho e Terra (2016).

3 Em seu texto de 2002, professor Cardim de Carvalho usa três tragédias de Shakespeare para entrelaçar incerteza e tomada de decisão em Keynes e Shackle, em um artigo que demonstra a sua grande e criativa erudição. 
premissas que eles assumem como verdadeiras ou, como aponta Keynes, pelo menos enquanto "elementos conhecidos com mais ou menos certeza" (1964, p. 147), a respeito dos quais se tomará alguma decisão, isto é, se chegará a alguma coisa nova e existente apenas na mente do decisor, fruto de seu processo lógico de raciocínio.

Esse ponto de chegada da razão (a que se pode chamar de decisão ou conclusão) não existe concretamente no ato decisório e, por isso, ele é um figment of imagination, uma imagem esperada pelo indivíduo da realidade vindoura. Diferentes, portanto, de escolhas sob risco, em que o conjunto dos resultados é sabido antecipadamente e assim é possível se realizarem cálculos probabilísticos, os fragmentos de imaginação fazem a escolha ser inerentemente incerta, porque, em função de os resultados não existirem, não se podem elencar resultados possíveis e nem se atribuírem probabilidades a cada evento em particular. No bojo das premissas, apenas as atuais são mais ou menos conhecidas, não as futuras, de tal sorte que sobre essas há apenas expectativa, contrapartida imanente da incerteza. Esta, por sua vez, é a incognoscibilidade do desconhecido, tornando os figments of imagination inexoráveis ao raciocínio e, logo, impossíveis de serem considerados irracionais. ${ }^{4}$

Carvalho (2002), novamente referenciando-se em Shackle (1979), argumenta que uma característica central da decisão é que ela é não-causada, isto é, ela é um ponto de partida que, embora raciocinada a partir do passado, é dele completamente livre, pois o futuro será ainda construído. Então, decisões são os atos presentes construtores do futuro: "o caminho é criado pelo caminhante ao caminhar, mas nem todas as trilhas podem ser abertas, ainda que não se saiba com antecedência quais realmente podem ser proficuamente exploradas" (CARVALHO, 2003, p. 180). O desfecho imediato de a realidade ser alterável pela própria ação dos indivíduos é o sistema não ter um padrão médio para o qual converge, seja no domínio do tempo, seja no do espaço: a realidade social é não-ergódica, ${ }^{5}$ qualidade que confirma a incerteza e, assim, a impossibilidade de cálculo probabilístico dos resultados futuros de uma decisão.

Logo, a incerteza é irremissível e, por sua vez, ela tem duas naturezas: a epistemológica, relativa à capacidade cognitiva do indivíduo, e a ambiental, que se refere à maneira pela qual a história da realidade social se constitui, impossível de ser antecipada

4 Por sinal, tanto Keynes (1921) quanto Shackle (1979) e o professor Cardim de Carvalho buscaram se contrapor à ideia de que apenas o raciocínio que ao final se mostra correto seja considerado válido e racional. Raciocínios cuja história mostra não terem sido antecipados corretamente são igualmente válidos e racionais.

5 O que inviabiliza a existência de expectativas racionais, como quer o mainstream da nova síntese neoclássica. 
(CARVALHO, 1988). ${ }^{6}$ Entendendo-se a incerteza fundamental como a impossibilidade de se terem todos os dados necessários ao conhecimento pleno, a incerteza ambiental é um reforço à epistemológica, pois, como apontam Ferrari Filho e Terra (2016): o agente não tem meios de conhecer todas as premissas necessárias à decisão integralmente fundamentada e a realidade social jamais oferecerá todos os dados, pois seus contornos futuros são impossíveis de serem conhecidos, uma vez que eles precisam ser criados com a própria interação das diversas decisões individuais.

Por isso, Carvalho (1988) aponta que uma consequência da ação humana criativa é as ciências humanas e sociais - ou morais, como ele chama, em linha com a natureza da ciência econômica para Keynes (1973) - não terem condições de serem deterministas, algo mais palatável somente às ciências naturais. Sendo o futuro um livro aberto, as histórias dos sistemas sociais são indeterminadas. Presente e passado podem legar características ao futuro, mas jamais definem o que ele será. Isso será consequência das inúmeras decisões descoordenadamente tomadas a todo o tempo pelos indivíduos.

As decisões econômicas, dessa forma, podem ser separadas em duas, de acordo com Carvalho (1988). Por um lado, decisões de curto prazo, como as concernentes à precificação e à produção, podem deter premissas cujas fontes são dados correntes mais bem conhecidos pelos empresários. Têm-se, assim, expectativas de curto prazo que são endógenas, pois podem se basear mais intensamente em dados mais bem conhecidos do passado e do presente. Isso não quer dizer, todavia, que o futuro repetirá o passado, ele é sempre indeterminado. Por outro lado, as expectativas atinadas às decisões de investimento, que criam capacidade produtiva, são de longo prazo e são “então, exógenas, porque elas não podem ser definitivamente relacionadas a nenhuma variável econômica corrente" (CARVALHO, 1988, p. 80).

Não obstante, Carvalho (2002) destaca que outra característica das escolhas é que elas são possíveis devido à realidade ter regras que a ordenam e que são formadas (i) por todo o aparato institucional e cultural da sociedade; (ii) pelas convenções - crenças compartilhadas, por vezes com raízes em figments of imagination, que, por se constituírem em convicção partilhada pelos agentes, os fazem compartir entre si a angústia da solidão das decisões individuais; (iii) pelo comportamento do homem médio não ser descomedido; (iv) pelas reações dos agentes à ação dos outros; (v) pelas políticas econômicas; e (vi) pelas tradições, entre outras causas. ${ }^{7}$ A existência dessa espécie de

6 Para mais sobre as naturezas da incerteza, veja Dequech (2004).

7 Diga-se de passagem, Keynes (1964, caps. 18 e 22) também faz tais destaques sobre regras que modulariam o comportamento econômico dos agentes, ao discutir por que, mesmo sujeito a crises peremptórias, o sistema em geral não incorre nelas tanto quanto poderia. 
ordem implica relações de causa-efeito que, embora desconhecidas, são limitadas justamente por restringirem a liberdade plena dos agentes. Daí o resultado de a ação humana não ser o caos; este é justamente o fruto de distúrbios intensos que fazem a ordem desaparecer e, nesses casos, a própria criação do futuro é inviabilizada, pois os indivíduos retraem-se à inação. Em matéria econômica, esses são os momentos de crise, com suas recessões e depressões.

A ordem, inclusive, é o que garante que a racionalidade do indivíduo se dê em etapas, do entendimento direto para o conhecimento direto e deste para a decisão, em uma cadeia causal racional (KEYNES, 1921). Os indivíduos sabem que desconhecem o futuro - eis a consciência da ignorância que Carvalho $(1988,2002,2003,2015)$ tão bem denomina -, mas o regramento social é inteligível e permite que se estabeleça sequência lógica, ainda que imbuída de intuição, no sentido de as premissas conduzirem a um conjunto desconhecido, mas limitado, de conclusões imagináveis.

$\mathrm{O}$ ato de se enfrentar a incognoscibilidade do desconhecido baseando-se em figments of imagination é o animal spirits, "uma espontânea urgência para agir ao invés da inação" (KEYNES, 1964, p. 161). Tais quais animais com sua capacidade extremamente restrita de raciocínio enfrentam o desconhecido para se alimentar e sobreviver, os indivíduos confrontam o percurso nebuloso entre suas decisões, imateriais, e a concretização da realidade que trará os resultados futuros delas. Não obstante, para exercer seu animal spirit, o indivíduo precisa confiar animadamente em suas figments of imagination: a materialização de uma decisão depende do estado de confiança (KEYNES, 1964) ou do grau de crença racional (KEYNES, 1921) do indivíduo em seus cenários imaginados.

O estado de confiança importa muito, por conta de uma característica indefectível da decisão: ela é crucial, isto é "um experimento autodestrutivo, um jogar o dado inerente e essencialmente de uma vez por todas, tudo ou nada" (SHACKLE, 1979, p. 58). Especialmente para as decisões exógenas de longo prazo, uma vez tomada a decisão, não há qualquer retorno, a história se altera e o ponto de partida se desfaz. A consciência da ignorância que os agentes possuem os faz conhecedores de que a decisão evanesce o local de embarque. Não há reversibilidade, destaca Carvalho (2015), diferente, portanto, dos postulados microeconômicos dos modelos do mainstream.

Por isso, o cálculo econômico dos agentes é defensivo e gradativo. Ele segue por etapas, como todo raciocínio: em primeiro lugar, prefere-se a liquidez plena, detendo-se moeda de forma precaucionária quando as expectativas são confiantemente desanimadoras. Reduzida a preferência pela liquidez, os indivíduos, então, buscam aferir o retorno de ativos financeiros mais líquidos do que os bens de capital, e, assim, a taxa de juros daqueles é um dos determinantes do investimento nestes e, por conseguinte, da dinâmica econômica. Só em última instância o indivíduo preferirá a inexoravelmente ilí- 
quida, exógena e crucial decisão de adquirir capital fixo, ato este intitulado por Carvalho (2003) como uma postura ofensiva, o animal spirits. Sempre que essa última não for o caso, a história contará que a "incerteza, como vista por Keynes, impôs um viés deflacionário na operação da economia, pois ela reduz a disposição dos agentes a gastar, [e atua] em favor da acumulação de ativos ilíquidos" (CARVALHO, 2015, p. 53).

Em suma, a contribuição do professor Cardim de Carvalho em termos da racionalidade humana sob incerteza deu-se em dois âmbitos. Por um lado, ele resgatou e sintetizou as contribuições de Keynes, do Treatise on Probability à TG, e as costurou com os desenvolvimentos sobre o tema feitos por Shackle (1979). Isso lhe permitiu oferecer um modelo de racionalidade sob incerteza, em que os papeis da incerteza, epistemológica e ambiental, dos figments of imagination, tais como as expectativas de futuro, da crucialidade das decisões, são centrais na ação humana, sendo que esta, por sua vez, é a criadora do futuro e, este, por fim, é o portador dos resultados esperados pelos agentes. O futuro é povoado de mitos a serem esclarecidos, "mas os mitos que caem vítima do esclarecimento já eram produto do próprio esclarecimento" (ADORNO e HORKHEIMER, 1985, p. 18): logo, a expectativa é a solução racional para a incognoscibilidade do desconhecido.

Por outro lado, o professor Cardim de Carvalho deu inúmeras ilustrações da racionalidade sob incerteza, como nas diferenças entre as decisões de curto e longo prazo, ou nas tragédias de Shakespeare, ou naquilo a que denominou comportamento defensivo, que prefere a liquidez da moeda quando dominam expectativas desanimadoras acerca do futuro. Não obstante, outra ilustração da racionalidade sob incerteza é a necessidade de sua compreensão por parte do economista que deseja investigar a economia como um objeto científico, como se verá na próxima seção, que descreve a contribuição do professor Cardim de Carvalho ao debate sobre o método em Keynes.

\section{A CONTRIBUIÇÃO DO PROFESSOR CARDIM DE CARVALHO AO DEBATE SOBRE O MÉTODO EM KEYNES}

Como referido anteriormente, há diversas controvérsias na teoria pós-keynesiana, sobre vários tópicos. Dentre elas, a questão do método em Keynes talvez seja uma das mais controvertidas, em função de o autor não ter deixado claro ao longo de sua obra qual seria seu método. ${ }^{8}$ Em seu texto de 2003, professor Cardim de Carvalho não denomina ou classifica o método da TG, apenas se atém a destacar algumas característi-

\footnotetext{
8 Não é intenção deste artigo debater as controvérsias metodológicas no pós-Keynesianismo, a não ser no que seja relevante para se ressaltar a contribuição do professor Cardim de Carvalho. Para uma descrição das diferentes posições sobre o método em Keynes, veja Ferrari Filho e Terra (2016).
} 
cas essenciais da forma pela qual o sistema econômico foi apreendido enquanto objeto científico no livro. Em meio ao elenco de características do método de Keynes na TG - em que se listam a herança marshalliana, ${ }^{9}$ os tempos histórico e expectacional, o recurso ao equilíbrio como um ponto de repouso não-gravitacional do sistema -, a compreensão da racionalidade humana sob incerteza é primordial.

O ponto de partida da caracterização de Carvalho (2003) é situar Keynes enquanto parte da tradição empiricista inglesa, sendo que a experimentação tinha três funções para esse autor. Por um lado, ela é uma forma de validação da teoria, de sua corroboração como pertinente para apresentar relações estáveis entre variáveis relevantes, que permitem aferir quais exercem maior efeito sobre os objetos a serem explicados. Por outro lado, a empiria é relevante pelo tipo de intervenção na realidade que ela permite: é da percepção da realidade que os dados teóricos são fornecidos ao pesquisador e é nessa assimilação do real que atuações externas, por exemplo, a política econômica estatal ou efeitos-manada decorrentes de racionalidade convencional, impactam. A empiria, neste sentido, embasa a filosofia da prática que, como sugere Andrade (2000), constitui o fundamento ideológico da postura de Keynes enquanto cientista: compreender a realidade não para contemplação, mas para nela intervir a bem de a transformar a favor de um interesse comum - no caso específico de Keynes, as eliminações do desemprego involuntário e da arbitrária e desigual distribuição de renda e riqueza do sistema capitalista, como ele deixa claro no capítulo 24 da TG.

Por fim, a empiria é a base da observação que permite a construção de conceitos observáveis e, então, de modelos teóricos. Embora Carvalho (2003) não assuma a indução como o método da TG, ela é o meio de se partir da observação de particulares para se alcançarem descrições gerais, como premissas e conclusões, respectivamente, caso se estivesse falando sobre a racionalidade sob incerteza de Keynes (1921). Por isso, Bresser-Pereira (2009) e Ferrari Filho e Terra (2016) argumentam que a indução foi basilar para Keynes, sendo que aquele a denomina "método histórico-dedutivo" enquanto que esses resgatam extensivamente Keynes (1921) para mostrar como ele defendeu a indução não somente como método científico, mas também como a maneira usual do próprio raciocínio humano. Para Keynes (1921), a indução possui dois submétodos, a analogia e a indução pura, ${ }^{10}$ sendo que em ambos a empiria é um meio importante de identificação de evidências particulares.

9 Carvalho (2003) lista as seguintes heranças marshallianas de Keynes: o uso das funções de oferta e demanda, o recurso às elasticidades, a compreensão da história como uma sucessão de fases de curto prazo e a importância do arcabouço histórico-institucional.

${ }^{10}$ Analogia é a comparação de objetos particulares e indução pura é a soma de evidências particulares. Para mais, veja Keynes (1921). 
Essas três funções da empiria são obviamente relacionadas entre si, embora não sejam a mesma coisa. Uma boa observação dos elementos particulares que comporão uma teoria a faz ser validada empiricamente. Teorias validadas, por sua vez, trazem consigo maiores condições de resultarem em efeitos práticos quando usadas para balizar intervenções na realidade que se observou. Não obstante, dentre as três funções da empiria, a segunda delas é a que mais interessa ao professor Cardim de Carvalho como característica essencial do método de Keynes na TG, pois a observação da realidade pelo investigador, para se obterem as evidências particulares sobre as quais teorizar, coloca o cientista, "de partida, nos sapatos dos agentes" (CARVALHO, 2003, p. 181).

Dessa forma, para o professor Cardim de Carvalho há uma clivagem de relevo entre o método de Keynes, o dos neoclássicos (este, ainda hoje, substancia o mainstream econômico) e, inclusive, o dos economistas políticos clássicos. Para os dois últimos, o cientista encontra-se acima dos agentes, analisando-os como um observador externo capaz de compreender a realidade em si e, portanto, de julgar o que é certo e, logo, o que deveria ser feito, e de diferenciá-lo do que é errado e precisa ser evitado. Este teorizar de forma independente do objeto, onipotente em relação a ele, ao que resulta das ações dele ou sobre ele, permite a construção de noções de verdade que tornam a realidade, em última instância, definida e a economia, assim, determinista. Descobrir essa verdade inerente às coisas é o dever do pesquisador nessa perspectiva $\mathrm{e}$ ao fazê-lo ele acredita ocupar uma posição privilegiada em relação ao homem médio, sabendo melhor do que esse o que deveria saber e fazer. Portanto, o mundo exterior é uma verdade em si mesmo e é livre dos sujeitos, de como eles o percebem.

Levando-se tal raciocínio à economia, por exemplo, explica-se por que nas construções teóricas que embasam o mainstream podem existir equilíbrios que funcionam como pontos normativos ótimos gerais para os quais o sistema necessariamente gravita; ou, por que bancos centrais independentes são a melhor institucionalidade para a política monetária; ou, ainda, por que seria irracional manter moeda como reserva de valor. A forma pela qual os agentes percebem o mundo não importa para o mundo, pois ele é algo em si e, em assim sendo, suas coisas são "atemporais e desprovidas de conteúdo, como o do agente maximizador de satisfação, que vive no vácuo histórico e institucional da teoria walrasiana” (CARVALHO, 2003, p. 176).

Para Keynes, enquanto as ciências naturais comportam determinismos, para qualquer outra ciência que lide com o ser humano como objeto, definições apriorísticas não cabem. Como dito anteriormente, Keynes definiu essas ciências, e dentre elas está a economia, como morais e elas "lidam com introspecção e com valores [...] com motivos, expectativas, incertezas psicológicas. É preciso estar-se em guarda constante contra tratar seu material como constante e homogêneo" (KEYNES, 1973, p. 300). Nesse aspecto, a perspicácia do professor Cardim de Carvalho foi a de apontar como essa postura científica de Keynes o fez compreender a economia a partir do sapato do sujeito teorizado. 
Para modelar o sistema capitalista como economia monetária da produção, Keynes colocou-se na posição de agente econômico em primeiro lugar e, logo, em uma posição diferente da escola neoclássico e da economia política clássica. Sendo a economia uma ciência moral, não há determinismo e, assim, a história está sempre sendo criada. Como é o indivíduo o sujeito criativo, como base para se entender o curso histórico-institucional das sociedades está apreender-se como se dá a decisão humana, isto é, o juízo racional sobre como se agir. Então, o primeiro passo para se modelar o sistema econômico é compreender a racionalidade humana e, nesse sentido, "para Keynes, o fato dominante da vida é a incerteza fundamental e incontornável que cerca o futuro" (CARVALHO, 2003, p. 176).

Nesse ponto, vale a pena construir a argumentação utilizando-se as claríssimas passagens do professor Cardim de Carvalho, para se esclarecer que "a preocupação com a tomada de decisão sob incerteza, porém, está na raiz do elemento ao mesmo tempo mais característico e mais particular do método de análise de Keynes, dizendo respeito à relação entre o analista e seu objeto" (CARVALHO, 2003, p. 177). O analista estar no sapato do agente analisado, observando as características particulares mais comuns dos indivíduos que, inelutavelmente, ele também é, permitiu a Keynes compreender que "mesmo os atos mais triviais da vida econômica são orientados pelo que esperamos seja o futuro" (CARVALHO, 2003, p. 176). Em conclusão,

uma teoria que ignore o fato essencial que o futuro é desconhecido e que todos nós tentamos de alguma forma nos defender desta ignorância fundamental não apenas descreverá inadequadamente o futuro que nos aguarda, mas será incapaz de explicar acuradamente o que fazemos do nosso presente. (CARVALHO, 2003, p. 176-177)

Não seria uma tal teoria a que Keynes faria em sua TG ou mesmo alhures. Para ele, se é fundamental compreender a racionalidade humana é porque ela conta a forma pela qual os agentes percebem o mundo e nele atuam, construindo-o. Assim, "não ser capaz de entender a mente do agente econômico inviabiliza a análise de como a economia opera” (CARVALHO, 2003, p. 179) e faz com que o pesquisador carregue uma série de preconceitos teóricos do mundo que ele descobriu como verdade independente dos agentes que realmente o compõem. Assim, é atentando-se ao comportamento individual e à racionalidade que o motiva que Keynes (1964) induz conceitos plenamente observáveis, como a propensão marginal a consumir e o inverso dela, a propensão a poupar, a preferência pela liquidez, a expectativa de retorno de bens de capital.

Não obstante, Carvalho (2003) aponta que o investigador, ao estar no sapato do agente pesquisado, faz, de fato, um movimento duplo. Ao mesmo tempo em que ele realiza a observação empírica do comportamento dos indivíduos, o pesquisador tam- 
bém se coloca na sua função de esclarecedor daquilo que observa. Cabe a ele, municiado pelos dados da realidade, apreender e descrever como os fatos que são percebidos se articulam entre si, montando um modelo de explicação do seu objeto de interesse. Tem-se, assim, o investigador como um sujeito ativo em dois âmbitos: o interno ao funcionamento do objeto, meio pela qual se conseguem as evidências a partir das quais teorizar, e o externo, posição na qual ele se coloca como organizador das evidências e ordenador da lógica relacional delas.

Carvalho (2003) chama a atenção, então, para outro recorte metodológico de Keynes: o nível de análise, algo que, diga-se de passagem, fundou a macroeconomia como disciplina autônoma da ciência econômica. Interpretar a racionalidade humana sob incerteza é precípuo para se conceber algo maior do que ela: o resultado das interações individuais, ou seja, o sistema econômico, “o objeto dos economistas keynesianos não são os comportamentos individuais per se [...] mas a interação dos indivíduos em suas atividades de produção e distribuição de bens e acumulação de riqueza” (CARVALHO, 2003, p. 181). Ademais,

ao economista cabe não apenas entender como se comportam os agentes econômicos que habitam o mundo real, mas também como estes comportamentos interagem para moldar as características observáveis em nível do sistema econômico. (CARVALHO, p. 181, grifos no original)

Pois bem, a se pegar a TG, como sugerem Ferrari Filho e Terra (2016), perceber-se-á que a estrutura do livro é uma representação fiel do que Carvalho (2003) descreve. Após Keynes (1964) mostrar o problema lógico e histórico de um elemento particular da teórica (neo)clássica, a que denomina enquanto o segundo postulado dela, o mercado de trabalho daquela teoria torna-se indeterminado, abrindo espaço lógico para que ele construa a sua teoria do emprego, que é o que ele passa a fazer a partir do princípio da demanda efetiva. Assim Keynes (1964) o fará, observando, conceituando e analisando detidamente diversos elementos particulares que explicam o comportamento da demanda, sobretudo aquela que interessa ao sistema, a agregada: os fatores objetivos que movimentam a função consumo e os subjetivos que definem o valor da propensão marginal a consumir; as expectativas de receita esperada como fundamento da eficiência marginal do capital, uma das determinantes do investimento; e a preferência pela liquidez da moeda como definidora da taxa de juros, a outra determinante do investimento. Esses elementos particulares se distribuem entre os capítulos oito e 17 da TG - por sinal, apenas depois de Keynes (1964) construir uma linguagem comum entre o livro e seus leitores nos capítulos quatro a sete. Somente ao final do livro, no capítulo 18 (dos 24 da TG), é o momento de Keynes 
reafirmar e generalizar a sua teoria, agora geral, do emprego, articulando sob uma lógica indutiva as relações entre todos os elementos particulares relevantes ao seu objeto que, analisados um por um, permitiram-lhe alcançar uma conclusão geral do sistema econômico em seu nível agregado.

Outrossim, perceba-se que os elementos explicativos do modelo da TG são três: a propensão marginal a consumir, a expectativa de receita da eficiência marginal do capital e a preferência pela liquidez. Todos são essencialmente subjetivos, envolvem figments of imagination, a se notarem pelos substantivos que os formam - propensão, expectativa e preferência. Ainda assim, são seus comportamentos ao longo do tempo que ditam a dinâmica agregada do sistema econômico. Logo, fica claro por que a racionalidade humana sob incerteza importa e por que a apreender, ao invés de a postular, é parte fundamental do trabalho do economista.

É importante salientar um último ponto. Carvalho (2003) aponta que Keynes recusou-se a usar a linguagem formal como meio de modelar e apresentar sua teoria. De fato, isto é perceptível desde o Treatise on Probability, quando Keynes (1921) argumenta que a formalização tem o mérito de evitar a ambiguidade de conceitos (algo que ele busca evitar com os acima mencionados capítulos quatro a sete, Livro Segundo da TG, intitulado "Definições e Ideias"), mas tem o demérito de tornar a teoria inacessível ao homem médio, que é o sujeito compreendido pela teoria e cuja prática na realidade ela visa a atingir. Corrobora-se, outra vez, a lógica apontada pelo professor Cardim de Carvalho de forma tão exata: teorizar, para Keynes, exige do cientista colocar-se no mundo ordinário, corrente, seja para perceber como a consciência da ignorância condiciona as decisões individuais, seja para usar a mesma linguagem comum que os agentes, seja para os entender, ainda que sob inexorável incerteza, como criadores de suas trilhas particulares e, em agregado, do sistema econômico.

Em síntese, a contribuição do professor Cardim de Carvalho à metodologia póskeynesiana foi mostrar que a forma pela qual Keynes concebeu a racionalidade humana sob incerteza é peça-chave para ele apreender seu sistema econômico na TG. Professor Cardim de Carvalho inova ao argumentar que, para tanto, o método de Keynes na TG o exigia descer aos sapatos do indivíduo teorizado para apreender a forma pela qual ele raciocina, ciente de sua ignorância, o mundo concreto no qual ele existe, vive e atua. Mesmo diante de toda a controvérsia atinente ao método em Keynes, não há construção prévia nesse sentido, tendo sido o professor Cardim de Carvalho o primeiro a fazê-la, ainda que sem apontar que é o método indutivo que permite essa generalização a partir de particulares dos quais se generaliza uma teoria. Mais do que entender a racionalidade humana sob incerteza em si, o professor Cardim de Carvalho deixa claro que compreendê-la é passo sine qua non para se analisar algo além dela, a economia monetária da produção. 


\section{CONSIDERAÇÕES FINAIS}

As contribuições do professor Cardim de Carvalho ao pós-Keynesianismo se deram em diversas frentes. As duas tratadas neste artigo, a racionalidade e o método, são talvez as menos ressaltadas na sua vasta obra. No que toca à racionalidade sob incerteza, professor Cardim resgatou e sistematizou a forma pela qual Keynes, desde o Treatise on Probability até a TG, desenvolveu-a. Para além, ele brilhantemente costurou a retomada que fez da obra de Keynes com o que Shackle (1979) havia desenvolvido sobre o tema, oferecendo ao leitor interessado um articulação inovadora e abrangente de ambas as referências.

O modelo de racionalidade sob incerteza oferecido pelo professor Cardim de Carvalho encadeou logicamente as premissas do conhecimento direto de Keynes (1921) com o estado de confiança fundamental ao exercício do animal spirits dos empresários na TG, para os quais as expectativas exógenas de longo prazo são as inspiradoras. Professor Cardim de Carvalho mostra, usando os termos de Shackle (1979), que essas expectativas são as figments of imagination inexoráveis ao raciocínio e, portanto, são parte relevante das decisões, sendo estas as criadoras cruciais do futuro e, por conseguinte, do sistema econômico.

Não obstante, buscou-se mostrar neste artigo que essa contribuição se complementa à outra, no campo da metodologia pós-keynesiana, pois a precisão do professor Cardim de Carvalho o fez perceber como Keynes concebia a racionalidade sob incerteza como fundamental para a compreensão do sistema econômico. Porém, para que isso não fosse meramente um postulado, ou um preconceito, como Carvalho (2003) também chamaria, o método de abordagem do fenômeno de Keynes na TG o fez ser, ao mesmo tempo, cientista e objeto analisado.

Keynes (1964), assumindo a posição de agente e observador, concebeu a TG levando em conta como os agentes percebem o mundo e o ressignificam com sua potência criativa - e o legado de tal posição metodológica à teoria pós-keynesiana remanesce, haja vista o chamado método do Real World de Davidson (1991) ou Chicke Dow (2001). Nessas condições, o método de Keynes (1964) consistia em apreender, ordenar e generalizar as regularidades empiricamente observadas dos comportamentos particulares, sendo que não apenas estes, mas sobretudo o resultado macroeconômico deles são o objeto de análise do economista. Enfim, não há economia sem racionalidade sob incerteza no campo teórico porque tal não há na realidade concreta. Não haverá economista pós-keynesiano, portanto, que não se ponha, concomitantemente, enquanto agente e investigador. 


\section{REFERÊNCIAS}

ADORNO, T.; HORKHEIMER, M. A dialética do esclarecimento. Rio de Janeiro: Zahar, 1985.

ANDRADE, R. P. A agenda do keynesianismo filosófico: origens e perspectivas. Revista de Economia Política, v. 2, n. 20, p. 76-94, 2000.

BRESSER PEREIRA, L. C. G. Os dois métodos e o núcleo duro da teoria econômica. Revista de Economia Política, v. 29, n. 2 (114), p. 163-190, 2009.

CARVALHO, F. J. C. Keynes on probability, uncertainty and decision making. Journal of PostKeynesian Economics, v. 11, n. 1, p. 66-81, 1988.

CARVAlHO, F. J. C. Mr. Keynes and the Post Keynesians. Aldershot: Edward Elgar, 1992.

CARVALHO, F. J. C. Decision-making under uncertainty as drama: Keynesian and Shacklean themes in three of Shakespeare's tragedies. Journal of Post Keynesian Economics, v. 25, n. 2 (189), 2002.

CARVALHO, F. J. C. “Características essenciais do método de Keynes na Teoria Geral”. In: CORAZZA, G. (org.). Métodos da Ciência Econômica. Porto Alegre: UFRGS, 2003, p. 175-188.

CARVALHO, F. J. C. Keynes on expectations, uncertainty and defensive behavior. Brazilian Keynesian Review, v. 1, n. 1, p. 44-54, 2015.

CHICK, V; DOW, S. Formalism, logic and reality: a Keynesian analysis. Cambridge Journal of Economics, v. 25, n. 6, p. 705-721, 2001.

DAVIDSON, P. Controversies in Post-Keynesian Economics. Brookfield: Edward Elgar, 1991.

DEQUECH, D. Uncertainty: individuals, institutions and technology. Cambridge Journal of Economics, v. 28, n. 3, p. 365-378, 2004.

FERRARI FILHO, F.; TERRA, F. H. B. Reflexões sobre o método em Keynes. Revista de Economia Política, v. 36, n. 1 (142), p. 70-90, 2016.

KEYNES, J. M. Treatise on probability. Londres: MacMillan and Co, 1921.

KEYNES, J. M. The general theory of employment, interest, and money. Nova York: HBJBook, 1964.

KEYNES, J. M. The general theory and after: defense and development (CWJMK, v. XIV). Londres: Cambridge University Press, 1973.

SHACKLE, G. L. S. Imagination and the nature of choice. Edimburgo: Edinburgh University Press, 1979. 